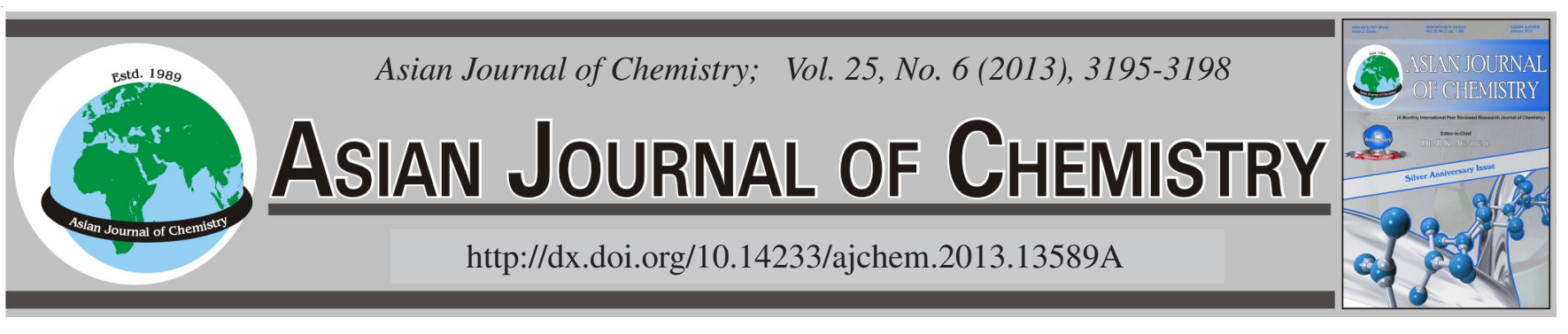

\title{
Preparation of Nano-Strontium Titanate Based on Glass Fiber Filter and Its Application in Speciation Analysis for Chromium
}

\author{
DONG ZHANG ${ }^{1, *}$ and YA JIE SuN ${ }^{2}$
}

${ }^{1}$ School of Environmental and Chemical Engineering, Shenyang Ligong University, Shenyang 110159, P.R. China

${ }^{2}$ Liaoshen Industry Group Co. Ltd., Shenyang 110045, P.R. China

Corresponding author: Fax: +86 24 24680345; Tel: +86 24 24680345; E-mail: sylgdxdong@ sina.com

\begin{abstract}
Nano-strontium titanate based on glass fiber filter was successfully prepared by sol-gel method and characterized using XRD and SEM. Its application in speciation of $\mathrm{Cr}(\mathrm{III})$ and $\mathrm{Cr}(\mathrm{VI})$ from water was studied. Adsorption and elution were investigated under different conditions. The results showed that the nano-strontium titanate could crystal based on glass fiber, gaining a new block adsorbent like a leaf. At normal temperature, the adsorbent had strong adsorption capacity for $\mathrm{Cr}(\mathrm{III})$ and $\mathrm{Cr}(\mathrm{VI})$ in water, but two forms of chromium show different adsorption capacities at different $\mathrm{pH}$ values, that is, $\mathrm{Cr}$ (III) selectively retained at $\mathrm{pH}$ 7-14, but $\mathrm{Cr}(\mathrm{VI})$ can't be adsorbed. Whereas $\mathrm{Cr}(\mathrm{VI})$ retained at $\mathrm{pH} 1-3$, but $\mathrm{Cr}(\mathrm{III})$ can't be adsorbed. Hence complete separation of the two forms of chromium is possible. Retained $\mathrm{Cr}(\mathrm{III})$ and $\mathrm{Cr}(\mathrm{VI})$ were eluted with $1 \mathrm{~mol} / \mathrm{L} \mathrm{HCl}$ and $2 \mathrm{~mol} / \mathrm{L} \mathrm{NaOH}$, respectively. Based on these, a simple and sensitive method for the speciation, separation and preconcentration of $\mathrm{Cr}(\mathrm{VI})$ and $\mathrm{Cr}(\mathrm{III})$ in environmental water was developed. The method was applied for the speciation of chromium in environmental water samples and measured by atomic absorption spectroscopy.
\end{abstract}

Key Words: Nano-strontium titanate, Glass fiber filter, Speciation analysis, Chromium, Separation, Preconcentration.

\section{INTRODUCTION}

In recent years, the field of nano-materials has had the attention, imagination and close scrutiny of scientists and engineers ${ }^{1}$. One of its most interesting properties is that most of the atoms are on the surface of the nanoparticle. The unsaturated surface atoms can bind with other atoms that possess strong chemical activity and produce high adsorption capacity. Vassileva et al. ${ }^{2,3}$ investigated the surface chemistry of high surface area oxides, e.g., $\mathrm{TiO}_{2}, \mathrm{CeO}_{2}$ and $\mathrm{ZnO}$ and found that these materials have a very high adsorption capacity towards metal ions and give promising results when used for trace elements preconcentration and analyses. Studies have only recently used nano-barium strontium titanate and nano-calcium titanate powders in the adsorption of heavy metals in water ${ }^{4-9}$ and the results indicated that nano-barium strontium titanate and nano-calcium titanate powders have higher adsorption capacity, but the nano- strontium titanate has not been studied. However, the nano-particles are so small that, when used in adsorption of metal ions, it was easy to coacervate and lose activity and are difficult to recover. Fixing nanometer powder onto different substrates corrects these problems ${ }^{10-13}$. Strontium titanate based on glass fiber filter has not been studied.

It is well known that the chromium metal and its compound are widely used in anodizing operation in the surface industry, chrome plating, leather tanning and various other industrial applications ${ }^{14}$. Chromium exists in the environment as chromium(III) and chromium(VI) oxidation states. The physiological effects of chromium on the biological system depend upon its oxidation state. $\mathrm{Cr}$ (III) may be considered as an essential trace element for the proper functioning of living organisms, on the contrary $\mathrm{Cr}(\mathrm{VI})$ can be toxic and has an adverse impact on the liver, lung and kidney ${ }^{15}$. For this reason, precise and accurate determination of both species in environmental samples is essential. The methods for determination and speciation of chromium(III) and chromium(VI) species mainly selective techniques are solid phase extraction followed by instrumental analysis ${ }^{16,17}$. In this work, a new method using strontium titanate based on glass fiber filter as sorbent has been developed for the separation and preconcentration of $\mathrm{Cr}(\mathrm{III})$ and $\mathrm{Cr}(\mathrm{VI})$ in water.

\section{EXPERIMENTAL}

$\mathrm{X}$-ray diffraction on the sorbents were performed using an X' Pert Pro X-ray diffractometer (PANalytical B.V., Netherlands) and images of the glass fiber filter and strontium titanate based on glass fiber filter (GFST) were taken using an S-3400N scanning electronic microscope (Hitachi Japan). The parameters for all machines were adjusted according to the manufacturer's recommendations. 
TABLE-1

FAAS OPERATING CONDITIONS

\begin{tabular}{ccccccc}
\hline Element & $\begin{array}{c}\text { Wave length } \\
(\mathrm{nm})\end{array}$ & $\begin{array}{c}\text { Spectral band width } \\
(\mathrm{nm})\end{array}$ & $\begin{array}{c}\text { Lamp current } \\
(\mathrm{mA})\end{array}$ & $\begin{array}{c}\text { Burner height } \\
(\mathrm{mm})\end{array}$ & $\begin{array}{c}\text { Acetylene gas } \\
\text { consumption }(\mathrm{mL} / \mathrm{min})\end{array}$ & $\begin{array}{c}\text { Air consumption } \\
(\mathrm{mL} / \mathrm{min})\end{array}$ \\
\hline Chromium & 391.1 & 0.4 & 12 & 5.0 & 1250 & 5000 \\
\hline
\end{tabular}

The concentration of chromium was determined using a WYX-9003A atomic absorption spectrometer (Shenyang Yi Tong Analytical Instrument Co. Ltd.), equipped with hollow cathode lamps for chromium and the operating conditions were summarized in Table- 1 .

The $\mathrm{pH}$ values were measured with a PHS-3C acidometer (Shanghai REX Instrument Factory, Shanghai, China) supplied with a combined electrode. The reagents, $\mathrm{Sr}\left(\mathrm{NO}_{3}\right)_{2}$ and citric acid, were analytical grade. Tetrabutyl titanate was chemically pure. Glass fiber filter was special for determination of TSP/ IP by gravimetric method in environmental monitoring (Shi Jia Zhuang Lage Sci and Development Co. Ltd.).

The reagents, $\mathrm{Cr}\left(\mathrm{NO}_{3}\right)_{3}$ was guarantee reagent, $\mathrm{HCl}$ and $\mathrm{NaOH}$ was Analytical reagent, $\mathrm{K}_{2} \mathrm{Cr}_{2} \mathrm{O}_{7}$ was primary reagent. Stock standard solutions of $\mathrm{Cr}(\mathrm{III})$ and $\mathrm{Cr}(\mathrm{VI})$ were prepared by dissolving appropriate amount of $\mathrm{Cr}\left(\mathrm{NO}_{3}\right)_{3}$ in $0.5 \mathrm{~mol} / \mathrm{L}$ $\mathrm{HCl}$ and $\mathrm{K}_{2} \mathrm{Cr}_{2} \mathrm{O}_{7}$ in distilled water. The water in this study was distilled water.

Preparation of the nano-strontium titanate based on glass fiber filter (GFST): Strontium titanate sol was synthesized by the citrate precursor method. For the preparation of the precursor solution, strontium nitrate, tetrabutyl titanate, citrate acid and ethylene glycol-1500 (EG-1500) were used as starting materials. First, a specific amount of tetrabutyl titanate was dissolved into ethanol. The mixture was stirred until it became transparent and yellow. Subsequently, citric acid were direct added to this solution on a magnetic stirrer and a clear solution was obtained. Then, strontium nitrate and EG-1500 solutions were added to this solution. The mixture was stirred continuously until it became a clear solution, pale brown in colour. Then, ammonium hydroxide solution was added to the precursor solution to adjust the $\mathrm{pH}$ value of 3 .

The glass fiber filter calcined at $500{ }^{\circ} \mathrm{C}$ for $1 \mathrm{~h}$ and was cooled to room temperature in a desiccator. It was immersed in the prepared strontium titanate sol for $15 \mathrm{~min}$ and then taken out and put in drying oven for drying at $105^{\circ} \mathrm{C}$. This process was repeated three times. The dried glass fiber filter was burned at $500{ }^{\circ} \mathrm{C}$ for $6 \mathrm{~h}$ under air atmosphere. Subsequently, it was cooled to room temperature in a desiccator. Nano-strontium titanate based on glass fiber filter (GFST) was immersed in 1 $\mathrm{mol} / \mathrm{L} \mathrm{HNO}_{3}$ for $20 \mathrm{~min}$. After washing to neutral with water, it was dried at $105^{\circ} \mathrm{C}$ and stored in a desiccator.

General separation and preconcentration procedure: A specific amount of $\mathrm{Cr}$ (III) and/or $\mathrm{Cr}$ (VI) solution were placed into $150 \mathrm{~mL}$ calibrated mark Erlenmeyer flasks with plug. Solutions were adjusted to a $\mathrm{pH} 13$ in the case of preconcentration of $\mathrm{Cr}(\mathrm{III})$ in the mark Erlenmeyer flask 1 and to $\mathrm{pH} 1$ in the case of preconcentration of $\mathrm{Cr}(\mathrm{VI})$ in the mark Erlenmeyer flask 2 . The preconcentration of investigated species was then performed simultaneously. After dilution to the mark of 50 with water, $0.1 \mathrm{~g}$ of GFST was added. Covered with a plug, shaken for $10 \mathrm{~min}$ in a bath shaker $(200 \mathrm{r} / \mathrm{min})$. Then the supernatant fluid was poured out. Retained $\mathrm{Cr}(\mathrm{III})$ and $\mathrm{Cr}(\mathrm{VI})$ were desorbed with $5 \mathrm{~mL}$ of $1 \mathrm{~mol} / \mathrm{L} \mathrm{HCl}$ and $2 \mathrm{~mol} / \mathrm{L} \mathrm{NaOH}$, respectively. Eluted samples were analyzed with flame atomic absorption spectrometry, the adsorption and preconcentration capacity was calculated.

\section{RESULTS AND DISCUSSION}

The X-ray diffraction patterns for glass fiber filter and GFST are shown in Fig. 1. It can be seen that the glass fiber filter was noncrystal (line 1), the sharps on the line 2 at 32.44 , $39.98,46.52,57.82$ and 67.84 can be attributed to strontium titanate. It can be concluded that strontium titanate loaded on the glass fiber filter had a perovskite structure. According the Scherrer equation, the average particle diameter of strontium titanate loaded on the glass fiber filter can be calculated ${ }^{4}$ and about $24 \mathrm{~nm}$.

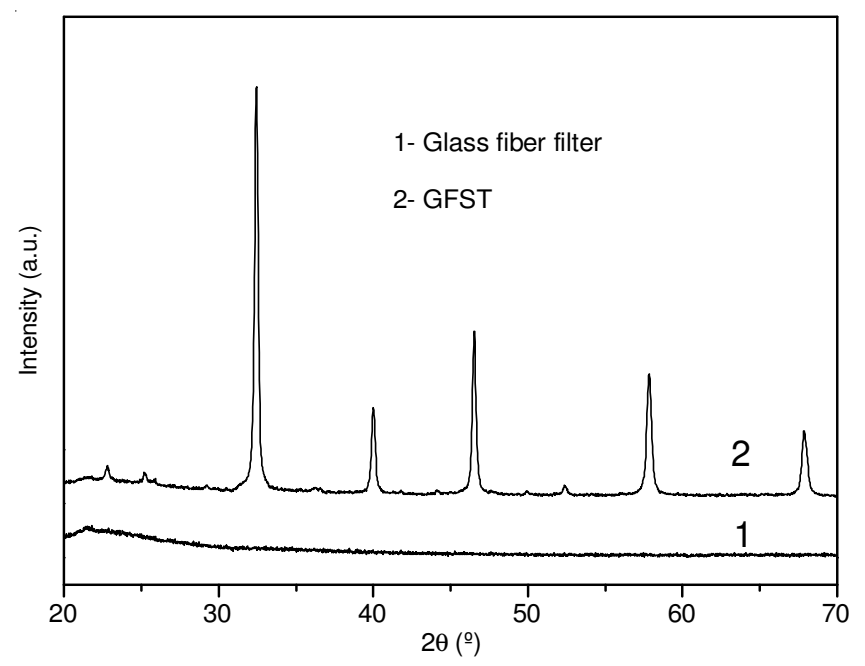

Fig. 1. XRD patterns of glass fiber filter and GFST

The SEM images of the glass fiber filter and GFST are shown in Fig. 2. The SEM images confirm that strontium titanate is shown on the surface of glass fiber. The strontium titanate could crystal based on glass fiber, gaining a new block adsorbent like a leaf.

Influence of pH on adsorption of $\mathrm{Cr}$ (III) and $\mathrm{Cr}$ (VI): Differences between sorption capacities of Cr(III) and Cr(VI) on the GFST surface provide the main reason for their selective preconcentration on the surface. Results concerning the effect of $\mathrm{pH}$ on the adsorption are presented in Fig. 3 and it is apparent that $\mathrm{pH}>7$ is appropriate for the adsorption of $\mathrm{Cr}(\mathrm{III})$ on GFST. The quantitative recovery of $\mathrm{Cr}(\mathrm{VI})$ is obtained at $\mathrm{pH}$ values $\leq 3$. Depending on the $\mathrm{pH}$, GFST can then selectively adsorb $\mathrm{Cr}(\mathrm{III})$ or $\mathrm{Cr}(\mathrm{VI})$, this makes GFST a very promising solid phase extractant in the separation of $\mathrm{Cr}(\mathrm{III})$ and $\mathrm{Cr}(\mathrm{VI})$.

Effect of contact time: At room temperature, the adsorption capacities for $\mathrm{Cr}(\mathrm{III})$ and $\mathrm{Cr}(\mathrm{VI})$ were determined with different shaking times (Fig. 4). The results indicate that the adsorption capacity increased with an increase in shaking time 

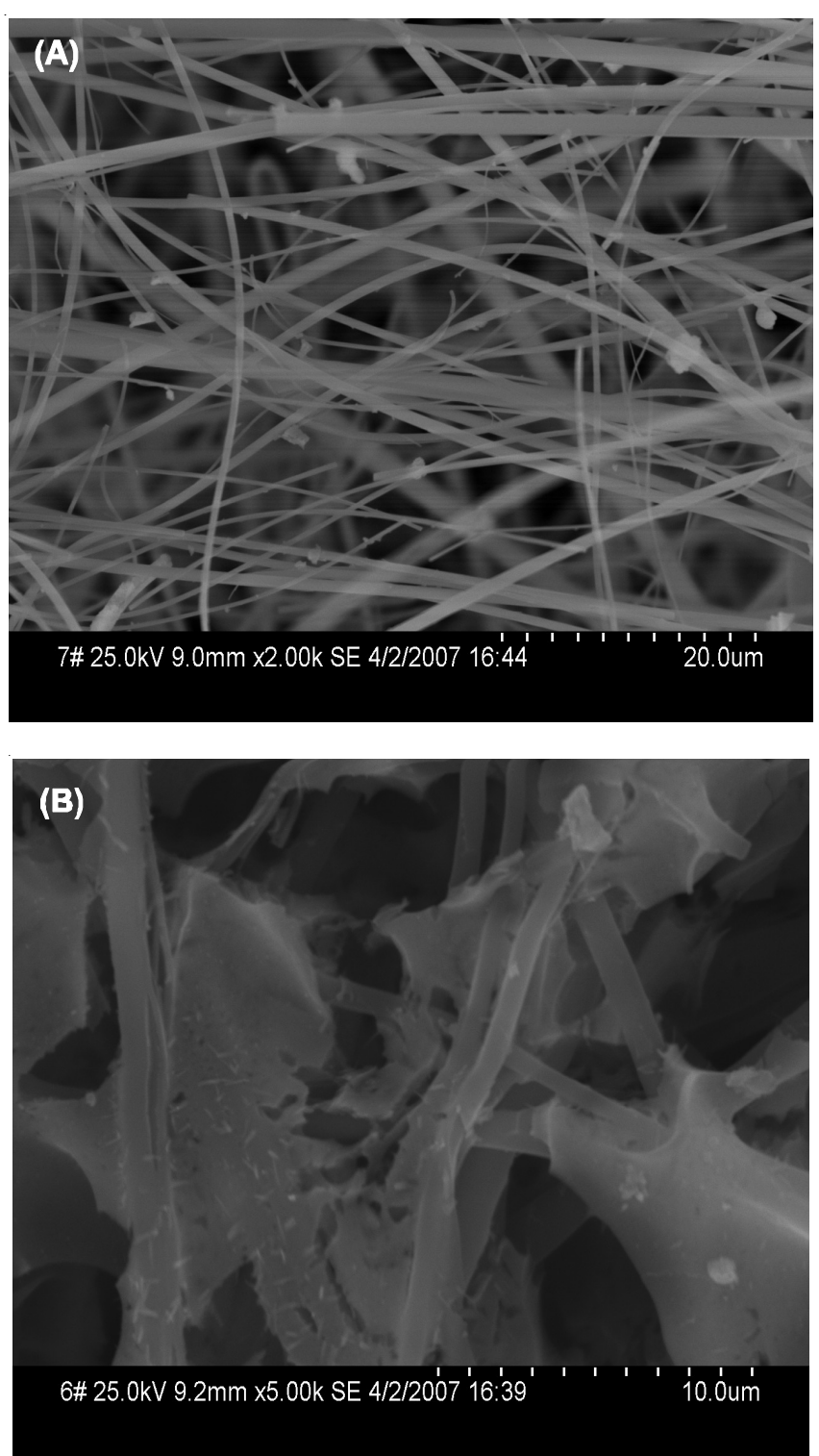

Fig. 2. (A) SEM images of glass fiber filter; (B) SEM images of GFST

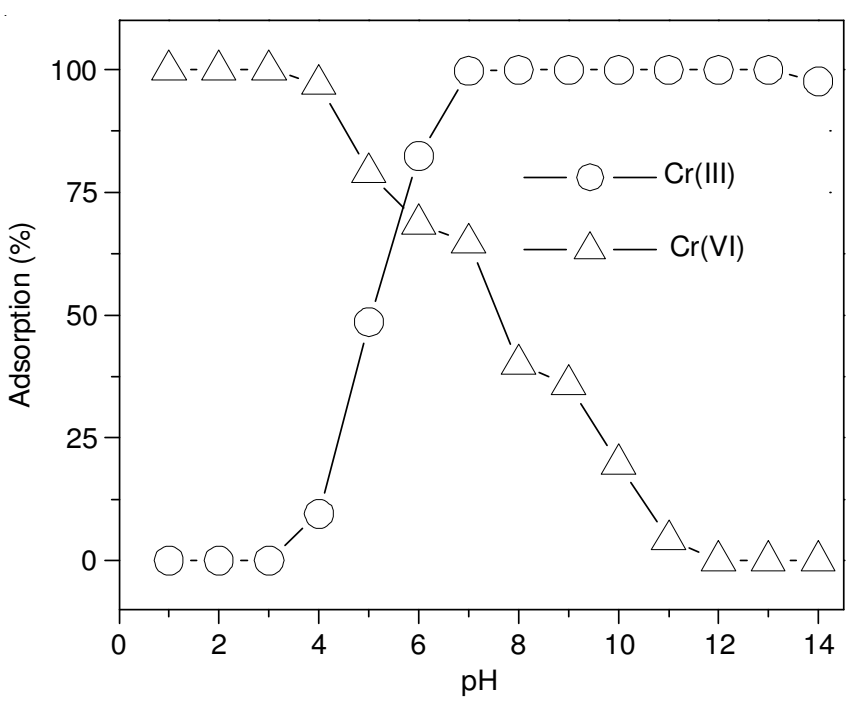

Fig. 3. Effect of $\mathrm{pH}$ on the adsorption

and reached equilibrium at $10 \mathrm{~min}$. Therefore, the shaking time was $10 \mathrm{~min}$ in this study.

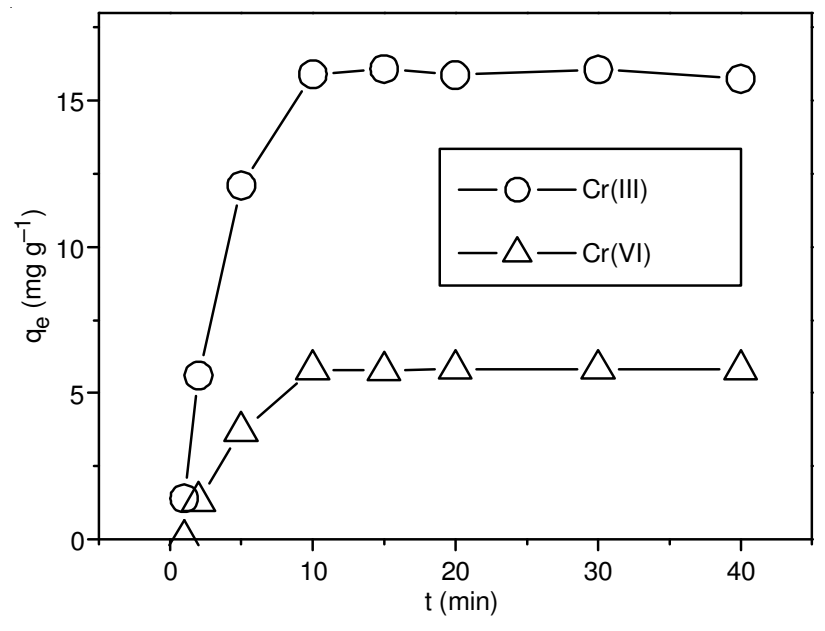

Fig. 4. Effect of contact time on adsorption

Adsorption capacity: According to Fig. 4, at room temperature, the static adsorption capacities of GFST to $\mathrm{Cr}$ (III) and $\mathrm{Cr}(\mathrm{VI})$ were $16.08 \mathrm{mg} / \mathrm{g}$ and $5.86 \mathrm{mg} / \mathrm{g}$, respectively.

Elution conditions: Fig. 3 shows that the adsorption of $\mathrm{Cr}(\mathrm{III})$ at $\mathrm{pH}=3$ and $\mathrm{Cr}(\mathrm{VI})$ at $\mathrm{pH}=12$, could be negligible. So, after the $\mathrm{Cr}(\mathrm{III})$ and $\mathrm{Cr}(\mathrm{VI})$ were adsorbed under the optimized adsorption conditions. Elution of $\mathrm{Cr}$ (III) and $\mathrm{Cr}(\mathrm{VI})$ from GFST surface, by $\mathrm{HCl}$ and $\mathrm{NaOH}$, respectively, at different concentrations and volumes was investigated. Recovery was quantitative (>95\%) with $5 \mathrm{~mL} 1 \mathrm{~mol} / \mathrm{L} \mathrm{HCl}$ and $2 \mathrm{~mol} /$ $\mathrm{L} \mathrm{NaOH}$ for $\mathrm{Cr}(\mathrm{III})$ and $\mathrm{Cr}(\mathrm{VI})$, respectively.

After elution, the GFST was dried and reused 10 times. Its adsorption performance did not decrease, indicating that this adsorption agent was very stable.

Effect of coexisting ions: The influences of possible matrix ions in the environmental samples and some transition metals were also examined. So various interfering ions were added into $50 \mathrm{~mL}$ volumetric flask containing $0.25 \mu \mathrm{g}$ of $\mathrm{Cr}(\mathrm{VI})$ and $\mathrm{Cr}$ (III). The recovery of heavy metal ions were determined according to experimental method with the error controlled within $\pm 5 \%$. The results showed that in the presence of 1000 $\mathrm{mg} / \mathrm{L} \mathrm{Na}^{+}, \mathrm{K}^{+}, \mathrm{NO}_{3}{ }^{-} ; 500 \mathrm{mg} / \mathrm{L} \mathrm{Mg}^{2+}, \mathrm{Ca}^{2+}, \mathrm{Mn}(\mathrm{VII}), \mathrm{SO}_{4}{ }^{2-}$; $200 \mathrm{mg} / \mathrm{L} \mathrm{Mn}(\mathrm{II}), \mathrm{Zn}^{2+}, 50 \mathrm{mg} / \mathrm{L} \mathrm{Al}^{3+}, \mathrm{Pb}^{2+}, \mathrm{Cd}^{2+}, \mathrm{Cu}^{2+}, \mathrm{Co}^{2+}$ and $\mathrm{Fe}^{3+}$. The recoveries of the $\mathrm{Cr}$ (VI) and $\mathrm{Cr}$ (III) were still above $95 \%$. It can be seen that the presence of major ions had no obvious influence on the recovery under the selected conditions.

Application to the real samples: The proposed method was applied to the separation, preconcentration and determination of $\mathrm{Cr}(\mathrm{III})$ and $\mathrm{Cr}(\mathrm{VI})$ in a natural river water sample (Hun-he river, Shenyang, China) and a lake water sample (Nan-hu lake, Shenyang, China) and a tap water sample collected from the water supply of Shenyang city. The river water and lake water samples were filtered through a $0.22 \mu \mathrm{m}$ membrane filter and analyzed immediately. The analytical results and the associated recovery are given in Table- 2 . The recoveries were 95.0-101.0\% for $\mathrm{Cr}$ (III) and 94.0-98.5\% for $\mathrm{Cr}(\mathrm{VI})$, which are excellent for trace analysis.

\section{Conclusion}

Nano-strontium titanate based on glass fiber filter (GFST) was successfully prepared and the new block adsorbent like a leaf was used for separation and preconcentration of $\mathrm{Cr}$ (III) 
TABLE-2

RESULTS FOR THE DETERMINATION OF Cr(III) AND Cr(VI) IN THE WATER SAMPLES

\begin{tabular}{|c|c|c|c|c|c|c|c|c|}
\hline \multirow{2}{*}{ Samples } & \multicolumn{2}{|c|}{ Found $(\mathrm{mg} / \mathrm{L})$} & \multicolumn{2}{|c|}{ Added (mg/L) } & \multicolumn{2}{|c|}{ Recovered (mg/L) } & \multicolumn{2}{|c|}{ Recovery percentage (\%) } \\
\hline & $\mathrm{Cr}(\mathrm{III})$ & $\mathrm{Cr}(\mathrm{VI})$ & $\mathrm{Cr}(\mathrm{III})$ & $\mathrm{Cr}(\mathrm{VI})$ & $\mathrm{Cr}(\mathrm{III})$ & $\mathrm{Cr}(\mathrm{VI})$ & $\mathrm{Cr}(\mathrm{III})$ & $\mathrm{Cr}(\mathrm{VI})$ \\
\hline \multirow{3}{*}{ Tap water } & \multirow{3}{*}{0.0126} & 0 & 0.0100 & 0.0100 & 0.0222 & 0.0094 & 96.0 & 94.0 \\
\hline & & 0 & 0.0200 & 0.0200 & 0.0328 & 0.0189 & 101.0 & 94.5 \\
\hline & & 0 & 0.0500 & 0.0500 & 0.0604 & 0.0482 & 95.6 & 96.4 \\
\hline \multirow{3}{*}{ River water } & \multirow{3}{*}{0.0235} & 0.0115 & 0.0100 & 0.0100 & 0.0330 & 0.0210 & 95.0 & 95.0 \\
\hline & & 0.0115 & 0.0200 & 0.0200 & 0.0431 & 0.0312 & 98.0 & 98.5 \\
\hline & & 0.0115 & 0.0500 & 0.0500 & 0.0717 & 0.0604 & 96.4 & 97.8 \\
\hline \multirow{3}{*}{ Lake water } & \multirow{3}{*}{0.1743} & 0.0213 & 0.1000 & 0.0100 & 0.2732 & 0.0309 & 98.9 & 96.0 \\
\hline & & 0.0213 & 0.2000 & 0.0200 & 0.3681 & 0.0406 & 96.9 & 96.5 \\
\hline & & 0.0213 & 0.5000 & 0.0500 & 0.6716 & 0.0691 & 99.46 & 95.6 \\
\hline
\end{tabular}

and $\mathrm{Cr}(\mathrm{VI})$. Two forms of chromium showed different exchange capacities at different $\mathrm{pH}$ values, viz. $\mathrm{Cr}$ (III) selectively retained at $\mathrm{pH}$ 7-14, whereas $\mathrm{Cr}(\mathrm{VI})$ retained at $\mathrm{pH}$ 1-3. Hence complete separation of the two forms of chromium was possible. Retained species were eluted with $5 \mathrm{~mL}$ of $1 \mathrm{~mol} / \mathrm{L} \mathrm{HCl}$ and 2 $\mathrm{mol} / \mathrm{L} \mathrm{NaOH}$. The method has been applied to the preconcentration and separation for flame atomic absorption spectrometric determinations of $\mathrm{Cr}(\mathrm{III})$ and $\mathrm{Cr}(\mathrm{VI})$ in surface water and tap water samples with satisfied results.

\section{REFERENCES}

1. K.J. Klabunde, Nanoscale Materials in Chemistry, New York (2001).

2. E. Vassileva, B. Varimezova and K. Hadjiivanov, Anal. Chim. Acta, 336, 141 (1996).

3. E. Vassileva and N. Furuta, Fresenius J. Anal. Chem., 370, 52 (2001).

4. H.D. Su and D. Zhang, J. Chem. Ind. Eng., 57, 2892 (2006).
5. D. Zhang, H.D. Su and H. Gao, Spectrosc. Spect. Anal., 28, 218 (2008).

6. D. Zhang, C.L. Zhang and P. Zhou, J. Hazard. Mater., 186, 971 (2011).

7. D. Zhang, W.J. Zhang and P. Hou, Asian J. Chem., 23, 4851 (2011).

8. D. Zhang, N. Li and D. Gao, Chin. J. Anal. Chem., 37, 1188 (2009).

9. D. Zhang, Asian J. Chem., 24, 5219 (2012).

10. D. Zhang, Z.G. Yuan, X. Guan and W.J. Zhang, Rare Metal Mater. Eng., 38, 2207 (2009).

11. Y. Liu, P. Liang and L. Guo, Talanta, 68, 25 (2005).

12. D. Zhang, W.J. Zhang, X. Guan, H. Gao and H.B. He, Spectrosc. Spect. Anal., 29, 824 (2009).

13. D. Zhang, P. Yu and X. He, J. AOAC Int., 93, 1925 (2011).

14. H.G. Seiler, H. Sigel and A. Sigel, Handbook on Toxicity of Inorganic Compound, Marcel Dekker Inc., New York, USA (1988).

15. C.D. Klaassen, Toxicology the Basic Science of Poisons, McGrawHill, New York (2001).

16. E. Martendal, H.F. Maltez and E. Carasek, J. Hazard. Mater., 161, 450 (2009).

17. I. Narin, Y. Surme, M. Soylak and M. Dogan, J. Hazard. Mater, 136, 579 (2006). 